\title{
Design and Simulation of Dual Axis Solar Tracker for Optimum Solar Energy Absorption
}

\author{
Sunil Kumar Jilledi*, Daniel Tesfazgi, Filmon Foto, Mahmud Ali, Abduselam Atta, \\ Alexander Yemane
}

Department of Electrical \& Electronics Engineering, Mai-Nefhi College of Engineering \& Technology, Asmara, Eritrea

Email address:

sunil.kumar@astu.edu.et (S. K. Jilledi)

${ }^{*}$ Corresponding author

\section{To cite this article:}

Sunil Kumar Jilledi, Daniel Tesfazgi, Filmon Foto, Mahmud Ali, Abduselam Atta, Alexander Yemane. Design and Simulation of Dual Axis Solar Tracker for Optimum Solar Energy Absorption. International Journal of Sensors and Sensor Networks. Vol. 7, No. 3, 2019 , pp. 34-43. doi: $10.11648 /$ j.jijssn.20190703.11

Received: July 31, 2019; Accepted: August 29, 2019; Published: September 19, 2019

\begin{abstract}
Solar energy is becoming one of the most expanding renewable energy it is getting more prominence. Sun trackers can substantially improve the electricity production of a photovoltaic (PV) system. This paper proposes a novel design of a dual-axis solar tracking PV system that utilizes the feedback control theory along with a four-quadrant light-dependent resistor (LDR) sensor and simple electronic circuits to provide robust system performance. Our project will include the design and construction of a microcontroller-based solar panel tracking system. In hardware development we utilize LDR's as sensors and two servo motors to direct the position of the solar panel. Dual-axis solar tracking allows more energy to be produced because the solar array is able to remain aligned perpendicular to the sun. In this paper to make better analysis Dual axis solar tracker is implemented for standalone system and simulation analysis is performed on the grid-connected PV station. To perform the experimental analysis the data is collected from Meteorology of Asmara and NASA. Comparative results have been presented between static and automatic solar dual-axis stand-alone systems. Moreover, comparison will be made among the output power results of our system with the conventional (Static) solar system. Simulation results have presented for the grid integrated system which shows better performance results.
\end{abstract}

Keywords: Dual-axis Solar Taker, PV Panel, Sensors, LDRS, Servomotor, Audrino

\section{Introduction}

Energy is the main factor in the development of a nation. An enormous amount of energy is extracted, converted, distributed and consumed in the global society daily. To provide a sustainable power production and safe world to the future generation, there is a growing demand for energy from the sun has produced energy for billions of years [1, 2]. Solar energy is the sun's rays (solar radiation) that reach the earth. Ultimately, directly or indirectly, the sun provides all the power we need to exist and supports all life forms.

The average Sun-Earth distance is about $1.5 \times 10^{11} \mathrm{~m}$ [3]. The diameter of the sun is about 109 times that of Earth, and its mass is about 330,000 times that of Earth, accounting for about $99.86 \%$ of the total mass of the Solar System [3]. The most popular are Photovoltaic (PV) Panels, where silicon solar cells convert solar radiation to electricity. Keeping the $\mathrm{PV}$-panels perpendicular to the sun's radiation maximizes the output. The angle at which the solar beam strikes the surface is called the solar incident angle. The closer the solar incident angle is to 90 degrees; the more energy is received on the surface. If a solar module or device is turned to face the sun throughout the day, its energy output increases. This practice is called tracking. There are many methods of harvesting solar energy like static, single-axis and dual-axis solar energy.

Using one axis of tracking can provide a significant power gain to the system. Single-axis trackers are placed into the following classifications: horizontal single-axis tracker (HSAT), vertical single-axis tracker (VSAT), tilted singleaxis tracker (TSAT), and polar aligned single-axis tracker (PASAT)[4]. However, these terms don't seem to be used in most articles discussing tracking methods. One article did 
mention that a TSAT at a tilt angle of $5^{\circ}$ increases the annual collection radiation by $10 \%$ compared to an HSAT. HSAT increases the annual collection radiation by $15 \%$ to a VSAT, and finally a PASAT increases the annual collection radiation by $10 \%$ over an HSAT [5]. Thus for one axis a PASAT or TSAT configuration would collect the most solar radiation. By further investigating we foresee this project significantly improving the quality of power gain by using dual-axis solar tracking system. Dual-axis trackers have two degrees of freedom that act as axes of rotation. Two common implementations are tip-tilt dual-axis trackers (TTDAT) and azimuth-altitude dual-axis trackers (AADAT) [6]. The orientation of the module with respect to the tracker axis is important when modeling performance. Dual-axis trackers typically have modules oriented parallel to the secondary axis of rotation. Dual-axis trackers allow for optimum solar energy levels due to their ability to follow the Sun vertically and horizontally. No matter where the Sun is in the sky, dualaxis trackers are able to angle themselves to be in direct contact with the Sun. Dual-axis tracking systems realize movement both along the elevation and azimuthal axes. These tracking systems naturally provide the best performance, given that the components have high enough accuracy as well. Dual-axis trackers have two degrees of freedom axis of rotation. Dual-axis solar trackers have both a horizontal and vertical axis trackers thus they can track the sun's apparent motion virtually anywhere in the world.

\section{Hardware and Software Component Descriptions}

\section{PV Panel}

Photovoltaic (PV) systems produce clean, reliable energy without consuming fossil fuels and can be used in a wide variety of applications on a larger scale, many utilities have recently installed large PV to provide consumers with solargenerated electricity solar cell is a solid-state semiconductor device that produces DC (direct current) electricity when stimulated by photons. When the photons contact the atomic structure of the cell, they dislodge electrons from the atoms. These leaves avoid which attracts other free available electrons. If a PN junction is fabricated in the cell, the dislodged photons flow towards the $\mathrm{P}$ side of the junction. The result of this electron movement is a flow of electrical current which can be routed from the surface of the cell through electrical contacts to produce power.

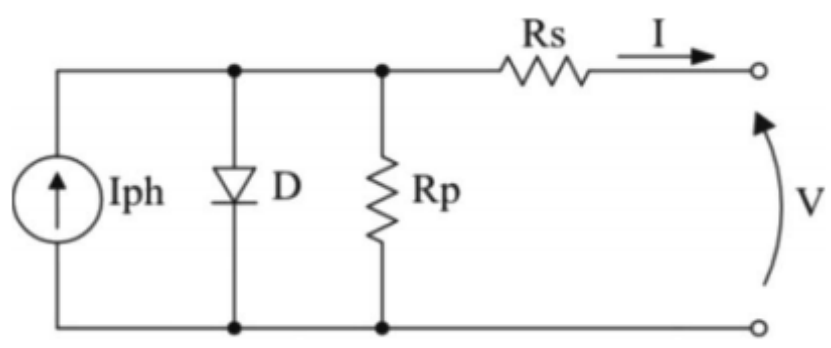

Figure 1. Equivalent model of the PV panel.
PV Panel Modeling:

The equivalent circuitry of a PV cell is shown in the below Figure, in which the simplest model can be represented by a current source in antiparallel with a diode and the nonidealities are represented by the insertion of the resistances $R_{s}$ (series resistance) and $\mathrm{R}_{\mathrm{p}}$ (parallel resistance).

The PV panel simulation model is based on the output current of one PV equivalent model, and its mathematical equation is represented by [14]:

$$
\mathrm{I}=\mathrm{I}_{\mathrm{ph}}-\mathrm{I}_{\mathrm{r}} *\left(e^{q \cdot(V+I \cdot R s) / \eta \cdot k \cdot T}-1\right)-\frac{V+I R s}{R p}
$$

Where $\mathrm{V}$ represents the output PV voltage of one PV panel, $I_{p h}$ is the photocurrent, $I_{r}$ is the saturation current, $q$ is the electrical charge $\left(1.6 \times 10^{-19} \mathrm{C}\right), \eta$ is the $p-n$ junction quality factor, $\mathrm{k}$ is the Boltzmann constant $\left(1.38 \times 10^{-23} \mathrm{~J} / \mathrm{K}\right)$, and $\mathrm{T}$ is the temperature (in kelvins). Equation (1) can be modified in order to present a null root when current I approach the real PV current. So, (Eqn 1) became (Eqn 2) as a function of its own PV current

$$
\mathrm{f}(\mathrm{I})=\mathrm{I}_{\mathrm{ph}}-\mathrm{I}-\mathrm{I}_{\mathrm{r}} *\left[e^{q(V+I R s) /(\mathrm{\eta} \cdot \mathrm{k} \cdot \mathrm{T})}-1\right]-\frac{V+I R s}{R p}
$$

Current I, with a null initial value, is utilized in an iterative process that approximates (Eqn 2) of its root, being obtained by the Newton-Raphson method (Eqn 3), which seeks the zero of the differentiable function

$$
X_{n+1}=X_{n}-\frac{f(X n)}{f^{\prime \prime}(X n)}
$$

Thus, the derivative of (Eqn 2) is presented in

$$
\mathrm{F}(\mathrm{I})=-1-\mathrm{I}_{\mathrm{r}} \cdot\left[e^{\mathrm{q} \cdot(\mathrm{V}+\mathrm{I} \cdot \mathrm{Rs}) /(\eta \cdot \mathrm{k} \cdot \mathrm{T})}\right] \frac{q R s}{\eta \mathrm{kT}}-\frac{\mathrm{Rs}}{R p}
$$

With the aforementioned equations and the I-V and P-V characteristics are part of the simulation (which will be explained in the simulation process), an embedded function to simulate the PV panel in MatLab/Simulink was created.

\section{Arduino Microcontroller}

Arduino microcontroller is easy to use a yet powerful single board. This Arduino microcontroller is used to control any controllable material by using a program that is compatible with it. With the Arduino board, you can write programs and create interface circuits read switches and other sensors, and to control motors very little effort. The Arduino microcontroller is used as a central processor in this Dual Axis Solar Tracking System.

\section{Sensors (LDR)}

A photoresistor or light-dependent resistor (LDR) or photocell is a resistor whose resistance decreases with increasing incident light intensity; in other words, it exhibits photoconductivity. A photoresistor is made of a high resistance semiconductor. If light falling on the device is of 
high enough frequency, photons absorbed by the semiconductor give bound electrons enough energy to jump into the conduction band. The resulting free electron (and its hole partner) conduct electricity, thereby lowering resistance.
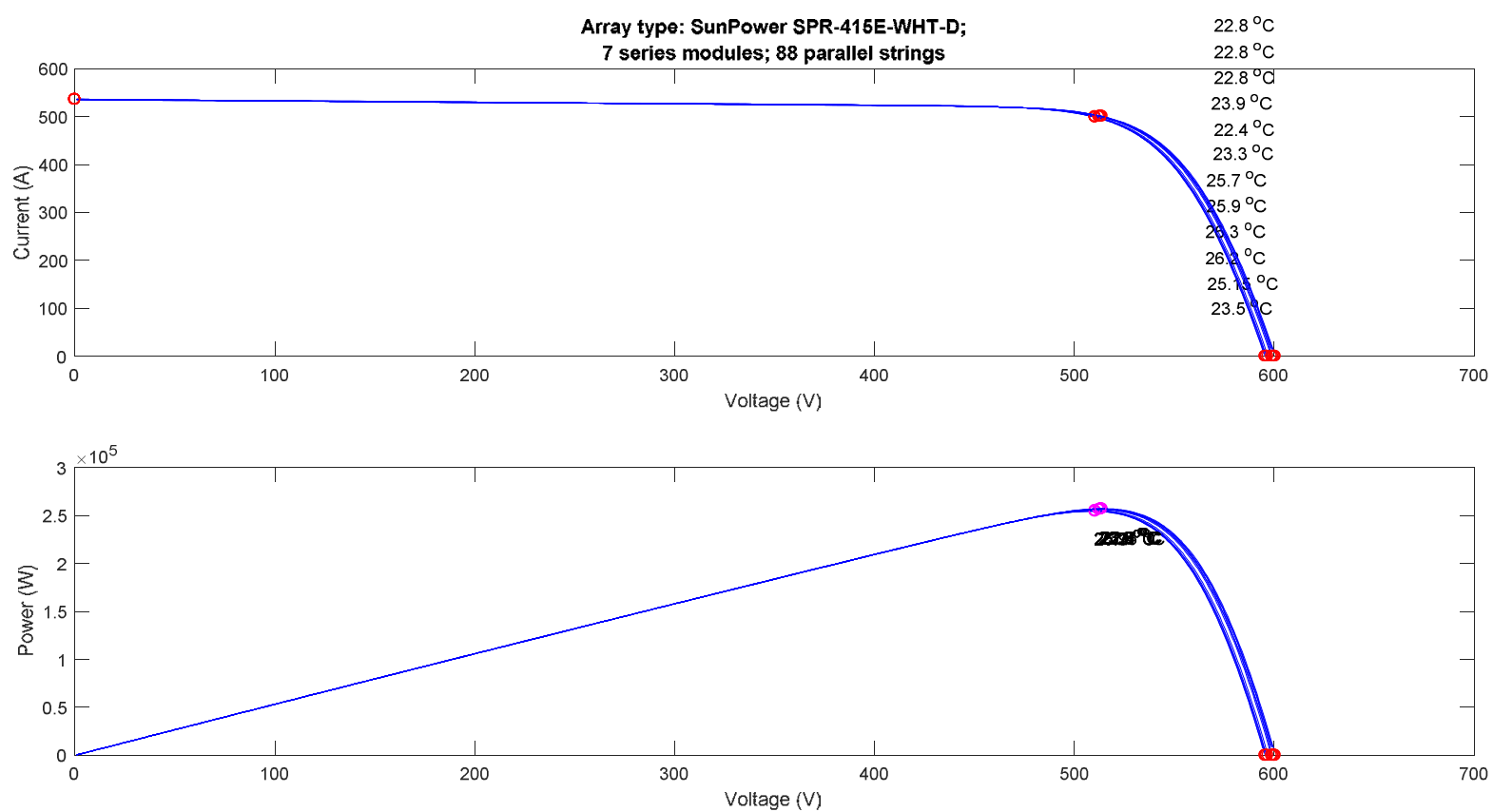

Figure 2. V-I and P-V characteristics of the PV array at specified temperatures.

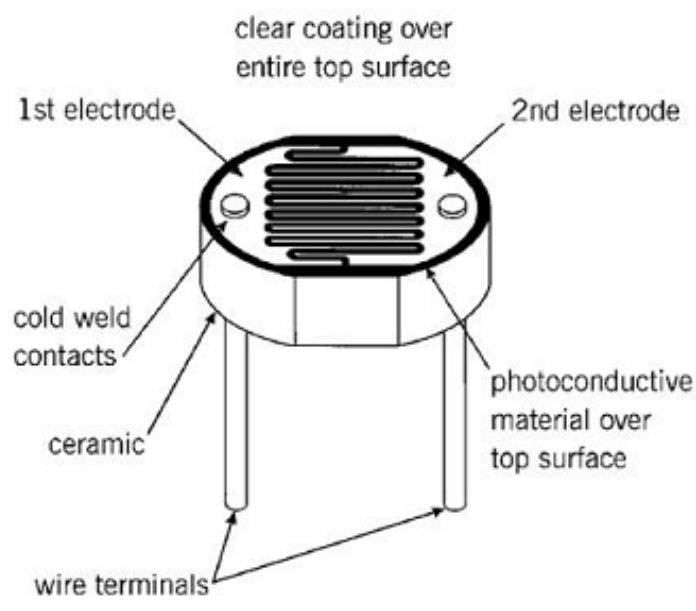

Figure 3. Light dependent resistor (LDR).

\section{Servo Motor}

A Servo motor is a linear or rotary actuator that provides fast precision position control for closed-loop control applications [12]. Unlike large industrial motors, a servo motor is not used for continuous energy conversion. The motor's speed is proportional to the difference between actual position and desired position. So if the motor is near the desired position it will turn slowly, otherwise it will turn fast. This is called proportional control.

Here in digital control, microprocessor or microcontroller are used for generating the PWM pulses in terms of duty cycles to produce more accurate control signals. The feedback signal corresponding to the present position of the load is obtained by using a position sensor. This sensor is normally a potentiometer that produces the voltage corresponding to the absolute angle of the motor shaft through gear mechanism. Then the feedback voltage value is applied at the input of error amplifier or comparator.

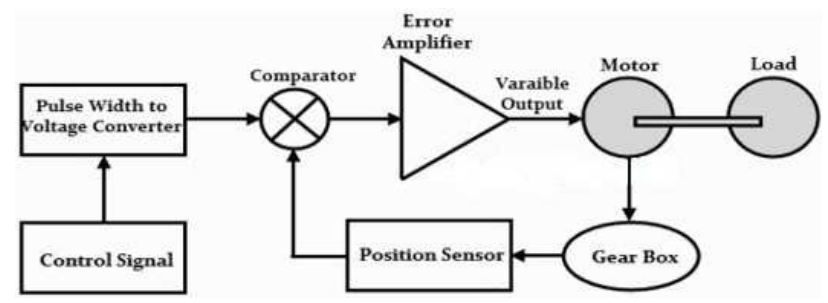

Figure 4. Control Mechanism of Servo motor.

\section{Modeling of Servomotors}

Elements to be modeled [12]

Amplifier and Motor

$$
\frac{\Theta}{\mathrm{V}}=\frac{\mathrm{Kv}}{\operatorname{Kes}(\mathrm{sTm}+1)(\mathrm{sTe}+1)}
$$

Position sensor

$$
\mathrm{K}_{\mathrm{f}}=\left(2^{\mathrm{n}}\right) /(2 \pi)
$$

Controller: The desired position signal is $\mathrm{R}(\mathrm{t})$ or simply ' $R$ ' actual position is ' $C$ '. Thus position error ' $E$ '.

$$
\mathrm{E}=\mathrm{R}-\mathrm{C}
$$

Basically, the PID controller is used in servo motors though variety of controllers can be implemented.

The proportional term $\mathrm{X}_{\mathrm{p}}$, 


$$
\mathrm{X}_{\mathrm{p}}=(\mathrm{P})(\mathrm{E})
$$

Where $\mathrm{P}$ represents the gain of the proportional part of the controller

The derivative term $\mathrm{X}_{\mathrm{d}}$,

$$
\mathrm{X}_{\mathrm{d}}=(\mathrm{sD})(\mathrm{E})
$$

Where $\mathrm{D}$ denotes gain of the derivative controller The integral term $\mathrm{X}_{\mathrm{i}}$,

$$
\mathrm{X}_{\mathrm{i}}=(\mathrm{I} / \mathrm{s})(\mathrm{E})
$$

Where I denote gain of the integral controller Sum of all three outputs

$$
\mathrm{X}=\mathrm{X}_{\mathrm{p}}+\mathrm{X}_{\mathrm{d}}+\mathrm{X}_{\mathrm{i}}
$$

The Transfer function $F(s)$, relating the output ' $x$ ' to position error $\mathrm{E}$ is,

$$
\mathrm{F}(\mathrm{s})=\mathrm{X} / \mathrm{E}=\mathrm{P}+\mathrm{sD}+\mathrm{I} / \mathrm{s}
$$

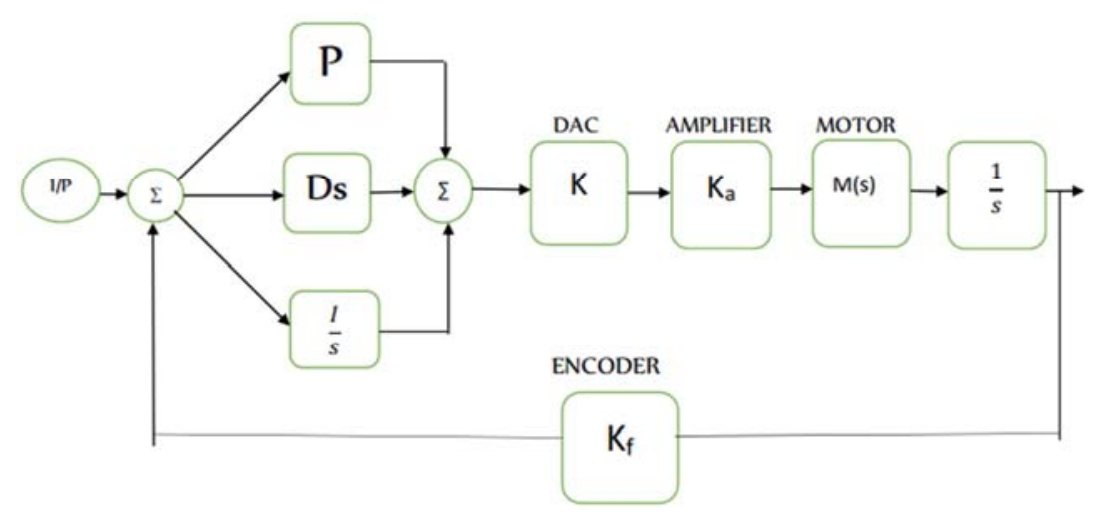

Figure 5. Transfer function of dcservo motor.

\section{System Implementationcircuit Diagram of the System}

The above diagram shows the basic hardware components that we have used in our project. All the input, sensing, controlling and output parts will be explained in this section.

1. Input And Sensing Part: Light Dependent Resistors (LDR).

2. Power Supply.
3. Controlling Part.

4. Output Part.

The main component in our project is the Arduino Microcontroller, LDR and Metal Gear Servo motor. Arduino Microcontroller is the heart of our project and its main function is to control/manage and prescription the whole system. It receives a signal from $L D R$ and sends a corresponding signal level according to the program loading on it, to move the MG90S motor to the proper direction.

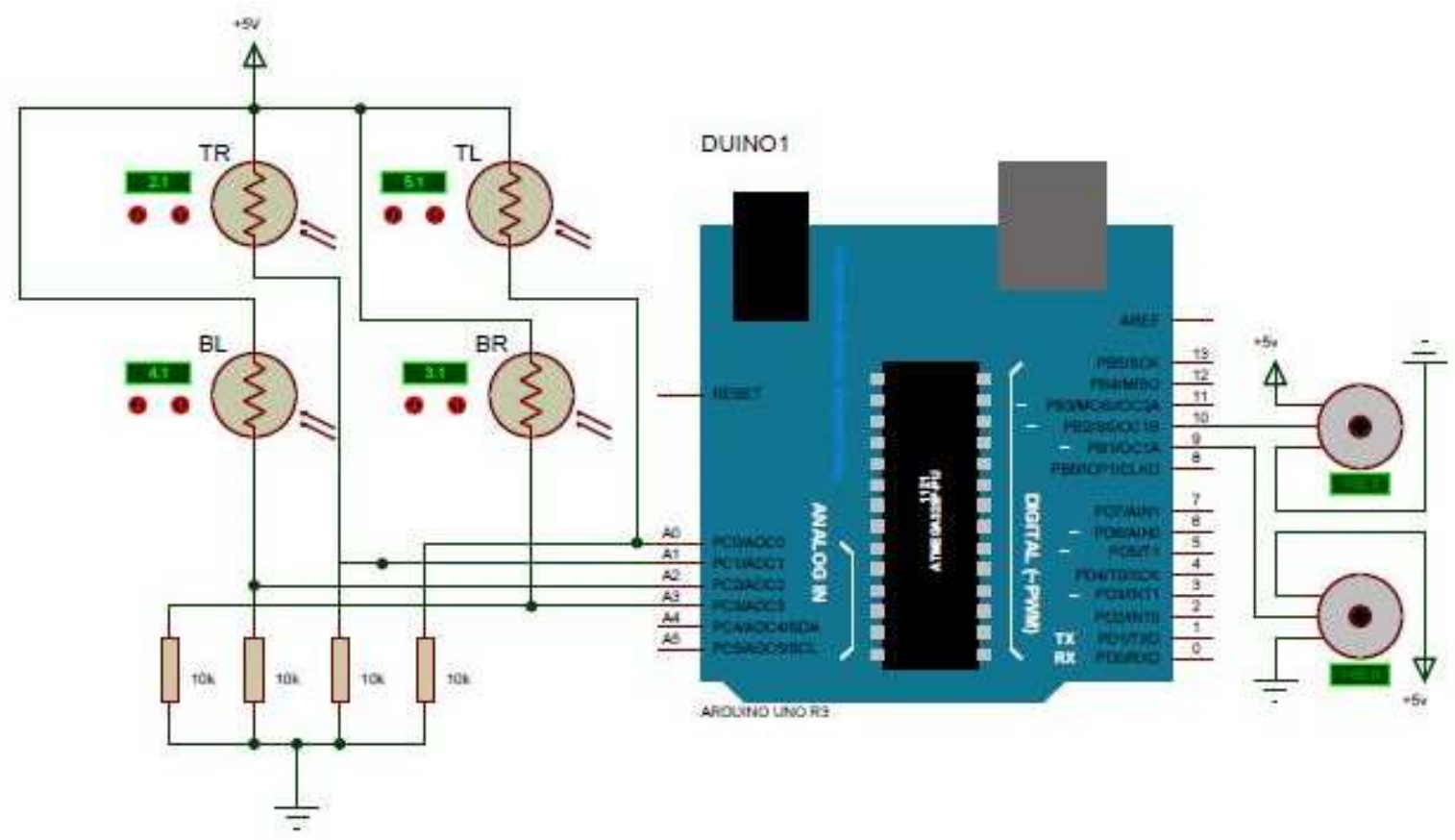

Figure 6. Circuit diagram of the Dual-Axis Tracking System. 
LDR is a device used as a sensing part, which converts the incoming intensity of light into its corresponding voltage level and sends the signal to the central part called the Arduino Microcontroller. Metal Gear Servo motor acts as an actuator, which receives a command signal from the Arduino and takes a necessary action according to the signal in order to track the sun perpendicularly by the PV panel to get maximum intensity of light from the sun. So we can use four LDRs and two MG90S motors to move the PV panel in both azimuths as well as elevation axes. Also, by introducing a 10 $\mathrm{k} \Omega$ Resistor we can protect the Arduino Microcontroller from incoming overvoltage effect by the LDRs.

\section{Flow Chart of the System}

The system tracks the Sun autonomously in azimuth and elevation angles. The whole working algorithms are summed up in the flowcharts shown in the below Chart. The sunlight intensity from four different directions is measured by the LDR-based sensing circuit. The voltages $\mathrm{V}_{\mathrm{TL}}, \mathrm{V}_{\mathrm{TR}}, \mathrm{V}_{\mathrm{BL}}$, and
$\mathrm{V}_{\mathrm{BR}}$ are defined as the sensing voltages produced by the top left, top right, bottom left and bottom right LDRs respectively. In an attempt to draw maximum power from the PV panel, the azimuth and elevation tracking processes can simultaneously proceed until the PV panel is aligned orthogonally to the sunlight. The tracker installation is not restricted to the geographical location.

Algorithm for Motor Control

The algorithm gives a description of the general steps undertaken for the project:

1. There is an input of voltage from the two pairs of LDRs.

2. The inputs are analog. They are converted to digital values.

3. The two digital values are compared and the differences between them are obtained.

4. The difference between the values obtained is the error proportional angle for the rotation of the servo motor.

5. If the LDR voltages are the same, the servo motors stop. Otherwise, the servo motor rotates until the difference becomes the same.

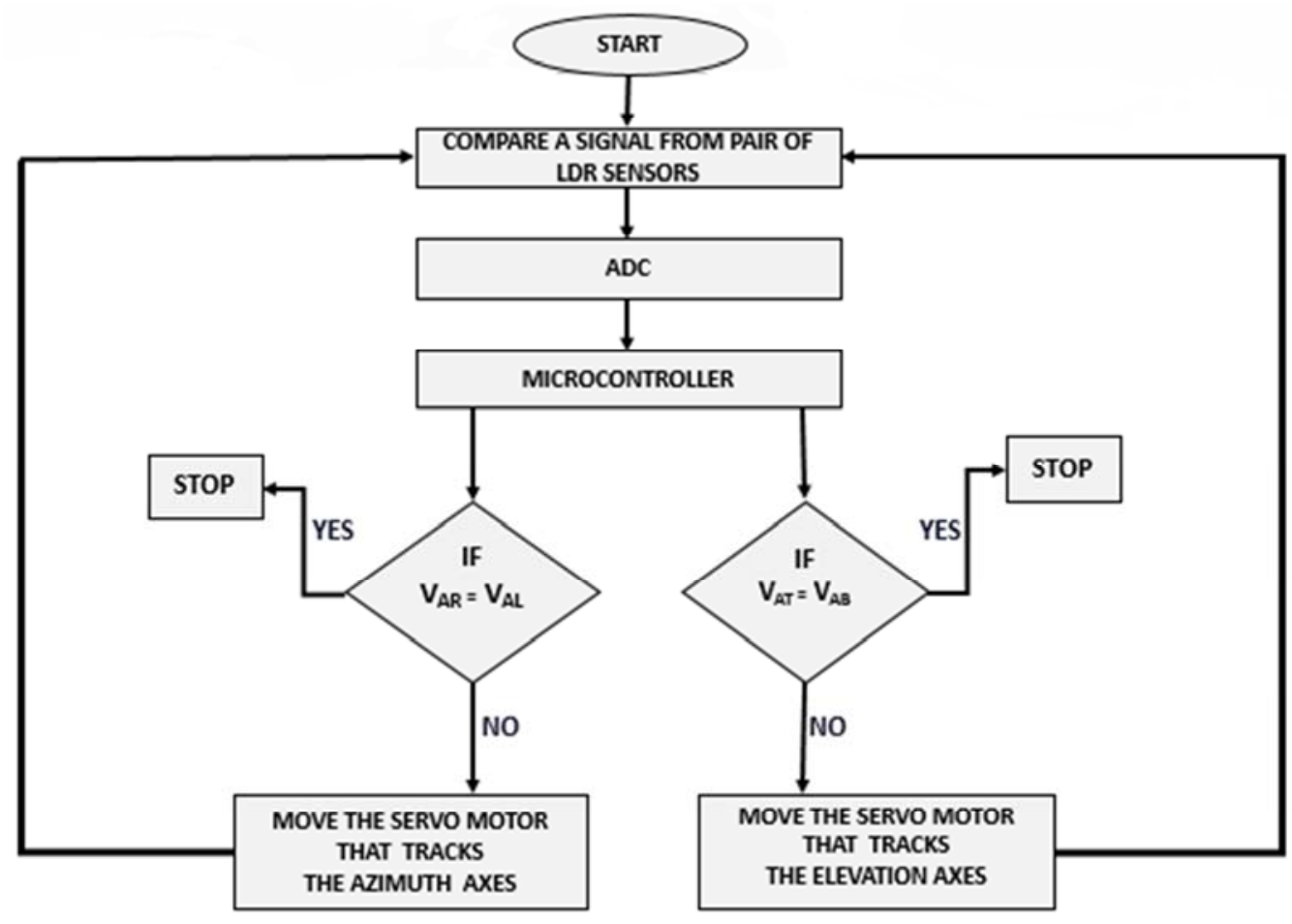

Figure 7. Flow chart.

\section{Simulation and Experimental Results}

Since we are familiar with experimental setup of the prototype in the previous sections. As per our expectation, the system is able to track the sun efficiently. The ratings of the panel that we take as a sample under a standard test condition are; $\mathrm{P}_{\max }=2.7 \mathrm{~W} ; \mathrm{I}_{\max }=320 \mathrm{~mA} ; \mathrm{V}=8.5 \mathrm{~V} ; \mathrm{STC}=$ $1000 \mathrm{~W} / \mathrm{m}^{2}$; TEMPERATURE $=25^{\circ} \mathrm{C}$.

All the experiments have been conducted in Asmara (Altitude $2325 \mathrm{~m}$, Latitude $15^{\circ} 17^{\prime} \mathrm{N}$ and Longitude $38^{\circ} 55^{\prime} \mathrm{E}$ ).
So the following table below shows the statistical data for voltage, current and power for every half an hour in a day. Even though the weather condition was varied throughout the day (because the measurements were taken in summer season), the results were achieved for both automatic as well as static solar system. (as mentioned in the table and graph below). The maximum power output of the static panel and dual-axis tracking system is found as 3.2049 watts and 4.7324 watts, respectively at $1: 30 \mathrm{pm}$. Nevertheless, in the early morning (sunrise) and in the later afternoon (sunset) the power value is very low.. However, the dual-axis tracker 
overwhelmed the static system even in the worst condition. The total power of static panel and the dual-axis tracking system throughout the day is 29.8856 watt and 42.66229 watt respectively. So the average power gain of dual-axis tracking system over the static panel is calculated below:

Let $\mathrm{A}=$ Average power for dual-axis solar tracking system $\mathrm{Z}=$ Power gain; $\mathrm{S}=$ Average power for static solar system

Formula: $(\mathrm{A}-\mathrm{S}) / \mathrm{S}=\mathrm{Z} \%$

So according to the formula above we are going to calculate the power gain (efficiency) of dual-axis tracker over static solar system from the given data in the above table:

Give data required: $\mathrm{A}=3.5552$ Watt $\mathrm{Z} \%=$ ?

$\mathrm{S}=2.4905$ Watt

Solution: $Z \%=(\mathrm{A}-\mathrm{S}) / \mathrm{S}, \mathrm{Z} \%=(3.5552-2.4905) /$ $(2.4905) \times 100 \%, Z \%=42.75 \%$

As can be seen from the above calculation we are able to improve the power output or power gain almost half of the static solar system that is by $42.75 \%$.
The prototype efficiency is extremely good; to know the model is suitable for higher ratings we made a simulation study. So, we are examining the system by using the Matlab Simulink library and the achieved result will be illustrated in the following simulation part. The PV array consists of 88 parallel strings. Each string has 7 SunPower SPR-415EWHT-D modules connected in series. Note that the model menu allows you to plot the I-V and P-V characteristics of the selected module or of the whole array. The table below shows whole specification of the selected module. Run the simulation and observe the resulting signals on the various scopes. When steady-state is reached (around $t=0.15 \mathrm{sec}$.), we get a PV voltage $\left(\mathrm{V}_{\mathrm{dc}}\right.$ mean) of $330 \mathrm{~V}$ and the power extracted $\left(\mathrm{P}_{\mathrm{dc}}\right.$ mean) from the array will vary from $70 \mathrm{KW}$ to $100 \mathrm{KW}$ according the input irradiance (See Figure below). These values correspond very well to the expected values from the PV module manufacturer specifications.

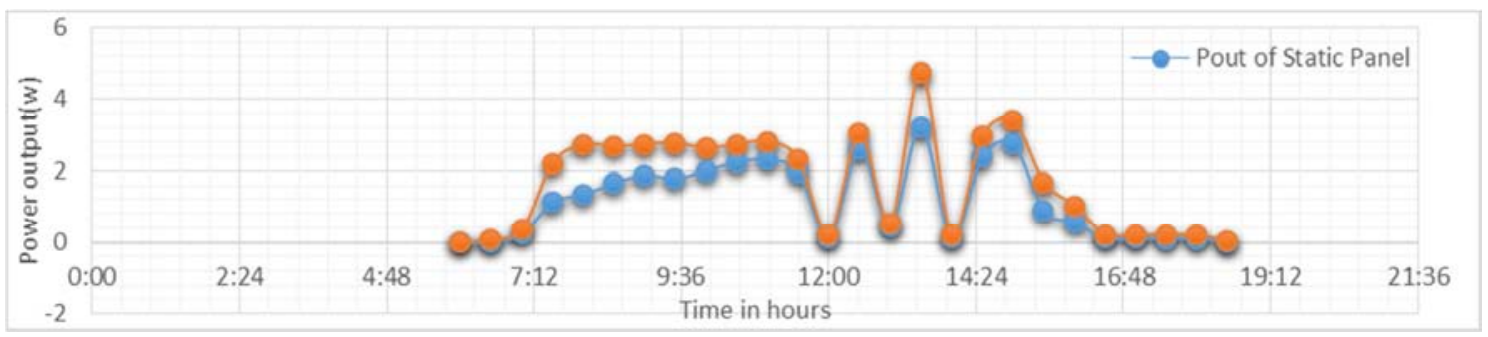

Figure 8. Power comparison between static and dual-axis PV panel.

\begin{tabular}{|c|c|c|c|c|c|c|c|c|}
\hline \multirow[b]{2}{*}{ TIME } & \multirow[b]{2}{*}{ Weather } & \multicolumn{3}{|c|}{ Automatic Solar Tracking System } & \multicolumn{3}{|c|}{ Static Solar System } & \multirow[b]{2}{*}{ Power(W) } \\
\hline & & Voltage(V) & Current(A) & Power(W) & | & Voltage(V) & Current(A) & \\
\hline $6: 00 \mathrm{AM}$ & Cloudy & 9.1 & 0 & 0 & I & 9 & 0 & 0 \\
\hline 6:30 AM & Cloudy & 9.83 & 0.008 & 0.07864 & 1 & 9.71 & 0 & 0 \\
\hline 7:00 AM & Cloudy & 11.58 & 0.03 & 0.3474 & 1 & 11.37 & 0.02 & 0.2274 \\
\hline $7: 30 \mathrm{AM}$ & Sunny & 11.6 & 0.19 & 2.204 & I & 11.23 & 0.1 & 1.123 \\
\hline 8:00 AM & Sunny & 12.36 & 0.22 & 2.7192 & 1 & 12.11 & 0.11 & 1.3321 \\
\hline $8: 30 \mathrm{AM}$ & Sunny & 12.11 & 0.22 & 2.6642 & 1 & 11.82 & 0.14 & 1.6548 \\
\hline 9:00 AM & Sunny & 11.89 & 0.23 & 2.7347 & 1 & 11.71 & 0.16 & 1.8736 \\
\hline 9:30 AM & Sunny & 12.01 & 0.23 & 2.7623 & 1 & 11.85 & 0.15 & 1.7775 \\
\hline 10:00 AM & Sunny & 11.93 & 0.22 & 2.6246 & 1 & 11.77 & 0.17 & 2.0009 \\
\hline $10: 30 \mathrm{AM}$ & Sunny & 11.87 & 0.23 & 2.7301 & I & 11.76 & 0.19 & 2.2344 \\
\hline 11:00 AM & Sunny & 11.67 & 0.24 & 2.8008 & 1 & 11.56 & 0.2 & 2.312 \\
\hline 11:30 AM & Sunny & 11.65 & 0.2 & 2.33 & 1 & 11.54 & 0.17 & 1.9618 \\
\hline 12:00 PM & Cloudy & 10.62 & 0.02 & 0.2124 & 1 & 10.23 & 0.01 & 0.1023 \\
\hline 12:30 PM & Sunny & 11.26 & 0.27 & 3.0402 & 1 & 11.21 & 0.23 & 2.5783 \\
\hline 1:00 PM & Cloudy & 10.91 & 0.05 & 0.5455 & 1 & 10.83 & 0.04 & 0.4332 \\
\hline 1:30 PM & Sunny & 12.04 & 0.31 & 4.7324 & 1 & 11.87 & 0.27 & 3.2049 \\
\hline 2:00 PM & Cloudy & 10.68 & 0.02 & 0.2136 & 1 & 10.61 & 0.01 & 0.1061 \\
\hline 2:30 PM & Sunny & 11.44 & 0.26 & 2.9744 & 1 & 11.33 & 0.21 & 2.3793 \\
\hline 3:00 PM & Sunny & 12.14 & 0.28 & 3.3992 & 1 & 11.92 & 0.23 & 2.7416 \\
\hline 3:30 PM & Cloudy & 11.15 & 0.15 & 1.6725 & 1 & 10.98 & 0.08 & 0.8784 \\
\hline 4:00 PM & Cloudy & 11.39 & 0.09 & 1.0251 & 1 & 11.16 & 0.05 & 0.558 \\
\hline 4:30 PM & Cloudy & 10.69 & 0.02 & 0.2138 & 1 & 10.55 & 0.01 & 0.1055 \\
\hline 5:00 PM & Cloudy & 10.61 & 0.02 & 0.2122 & 1 & 10.47 & 0.01 & 0.1047 \\
\hline 5:30 PM & Cloudy & 10.15 & 0.02 & 0.203 & 1 & 10.01 & 0.01 & 0.1001 \\
\hline 6:00 PM & Cloudy & 9.79 & 0.02 & 0.1958 & 1 & 9.57 & 0.01 & 0.0957 \\
\hline 6:30 PM & Cloudy & 8.75 & 0.003 & 0.02625 & 1 & 8.54 & 0 & 0 \\
\hline TOTAL & $\cdots$ & 289.22 & 3.551 & 42.66229 & I & 284.71 & 2.58 & 29.8856 \\
\hline AVERAGE & & & & 3.5552 & I & & & 2.4905 \\
\hline
\end{tabular}

Figure 9. Statistical Data for Voltge, Current and power for every half an hour in a Day. 


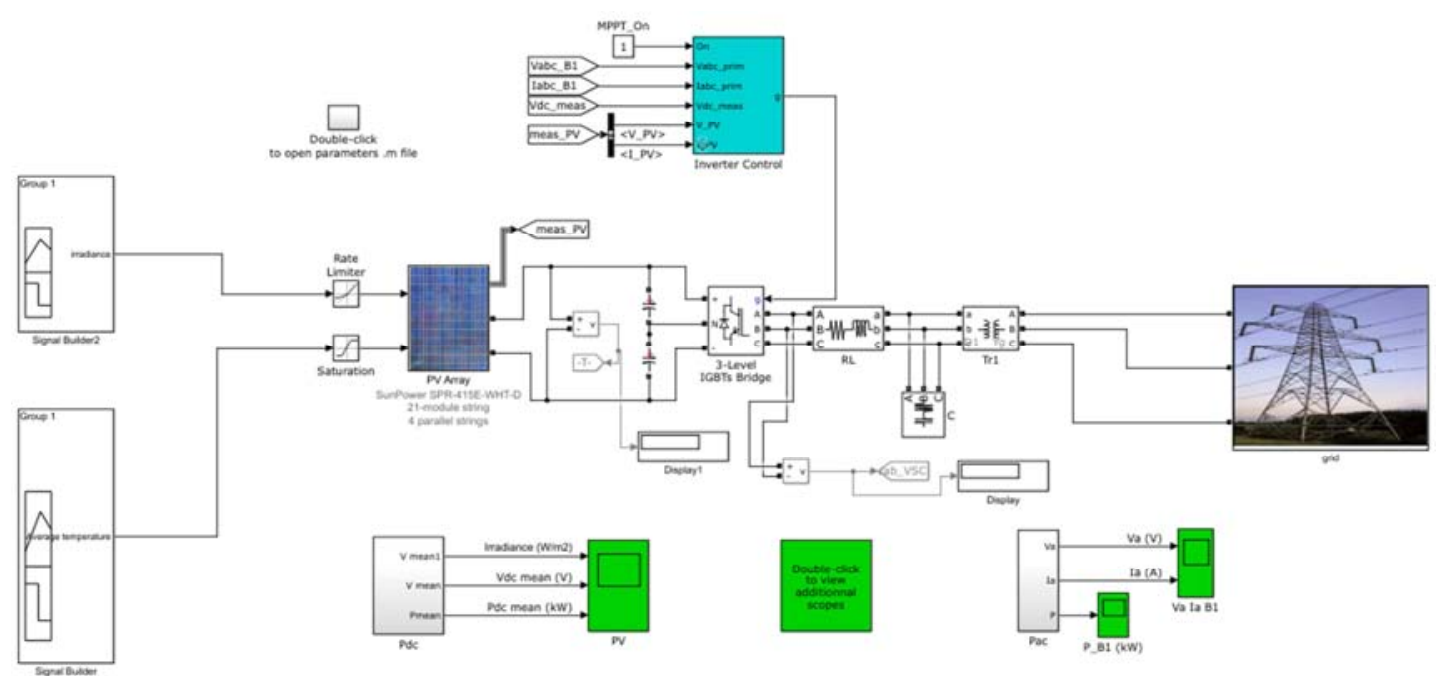

Figure 10. Circuit diagram of our project simulation.

The Simulation Process of 250-kW Grid-Connected PV Array is shown in Figure 8.

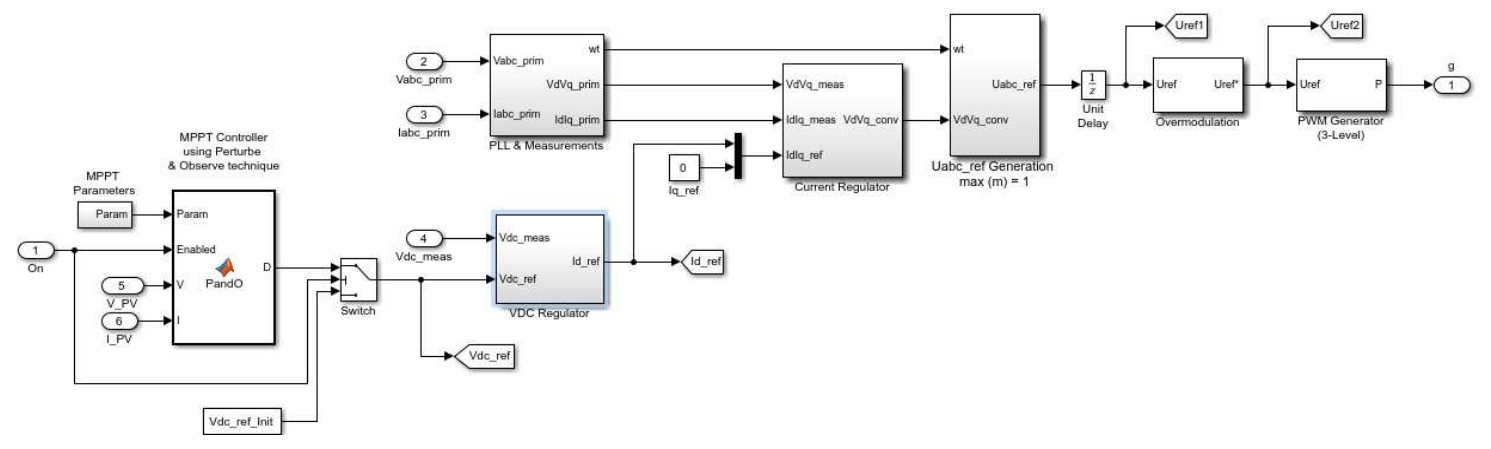

Figure 11. Inverter controller of the solar grid integrated the system.
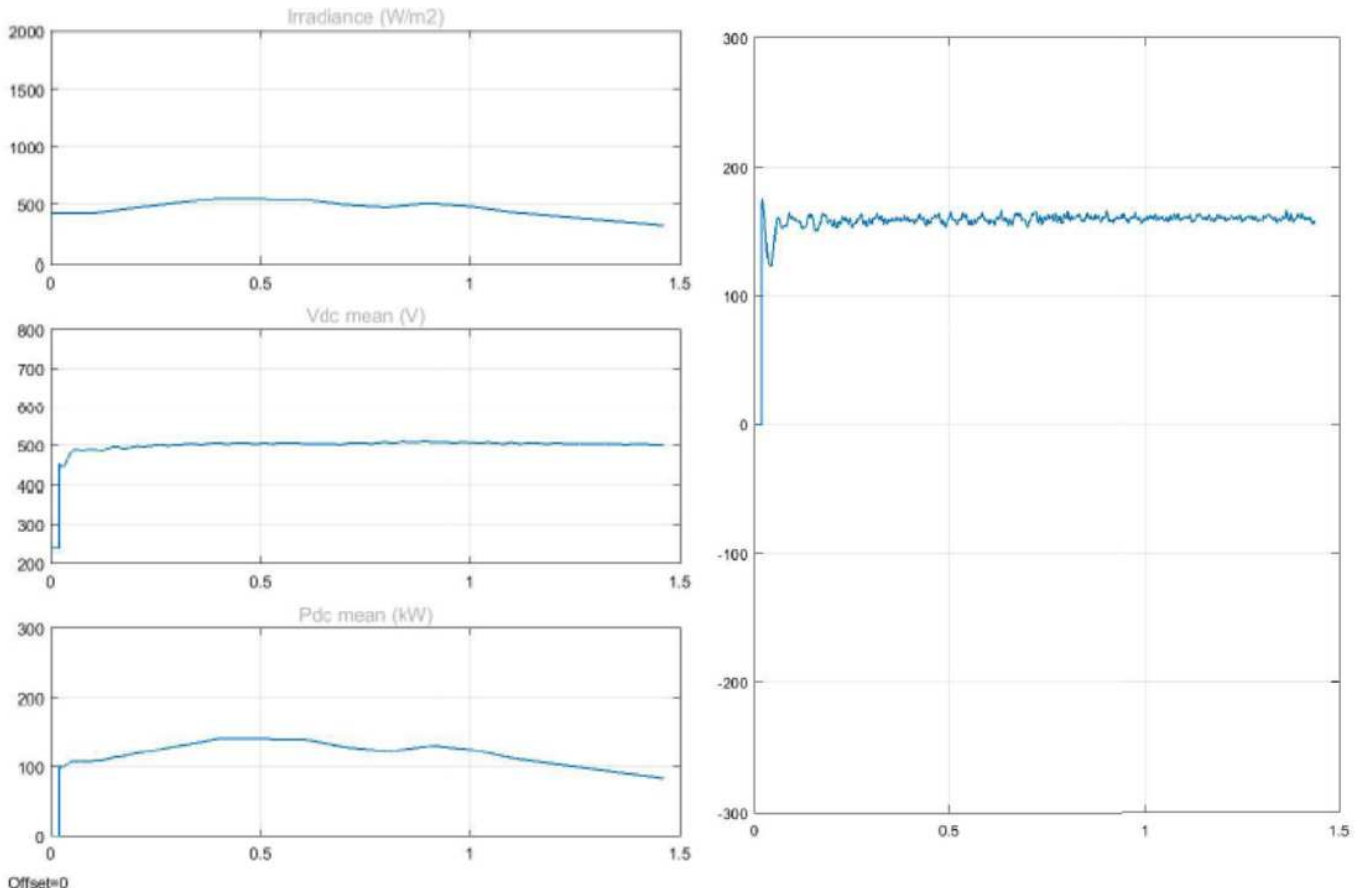

Figure 12. Output characteristics of static PV array without MPPT. 

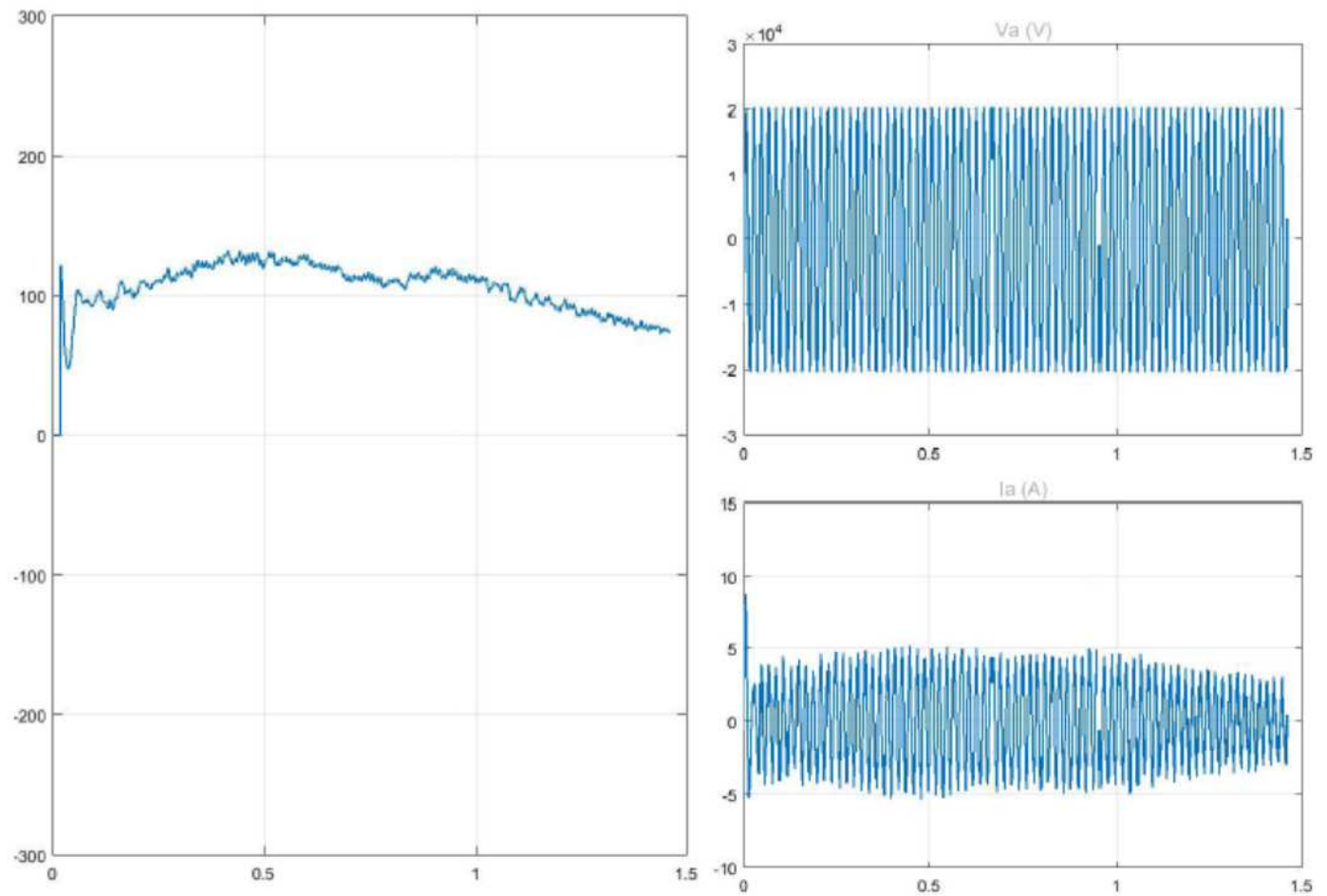

Figure 13. Output characteristics of PV array with dual-axis tracker and MPPT.

But, when we applied the dual-axis tracker with MPPT, the initial input irradiance to the PV array model is taken to be almost constant since the PV panel faces the sun perpendicular all the time and the operating temperature is given according the data collected. When steady-state is reached (around $\mathrm{t}=0.15 \mathrm{sec}$.), we get a $\mathrm{PV}$ voltage $\left(\mathrm{V}_{\mathrm{dc}}\right.$ mean) of about $500 \mathrm{~V}$ and the power extracted $\left(\mathrm{P}_{\mathrm{dc}}\right.$ mean) from the array will be about $190 \mathrm{KW}$ according the input irradiance. So as we can observe also from the output characteristics above obtained from the simulation, there is a great deal of difference in power output. Necessary Data Related with the Site: We have collected monthly average irradiance and temperature of Asmara (Eritrea) from the NASA statistical report. The selected or privileged site is located in a very suitable place since the panels yield maximum power output at room temperature.

Altitude $2325 \mathrm{~m}$ above sea level.

Degree Latitude $15^{\circ} 17^{\prime} \mathrm{N}$.

Degreelongitude $38^{\circ} 55^{\prime} \mathrm{E}$.

Table.1 Mean solar radiation and Temperature of Asmara taken from NASA.

\begin{tabular}{|c|c|c|c|c|c|c|c|c|c|c|c|c|c|}
\hline & Jan & Feb & Mar & Apr & May & Jun & Jul & Aug & Sep & Oct & Nov & Dec & Annual \\
\hline $\mathrm{KWh} / \mathrm{m}^{2} / \mathrm{d}$ & 5.18 & 5.72 & 6.23 & 6.74 & 6.68 & 6.62 & 6.05 & 5.77 & 6.19 & 5.87 & 5.27 & 4.90 & 5.93 \\
\hline AvgTemp $\left({ }^{\circ} \mathrm{C}\right)$ & 23.4 & 25.15 & 26.1 & 26.2 & 25.9 & 25.6 & 23.3 & 22.3 & 23.8 & 22.7 & 22.7 & 22.7 & 24.15 \\
\hline
\end{tabular}

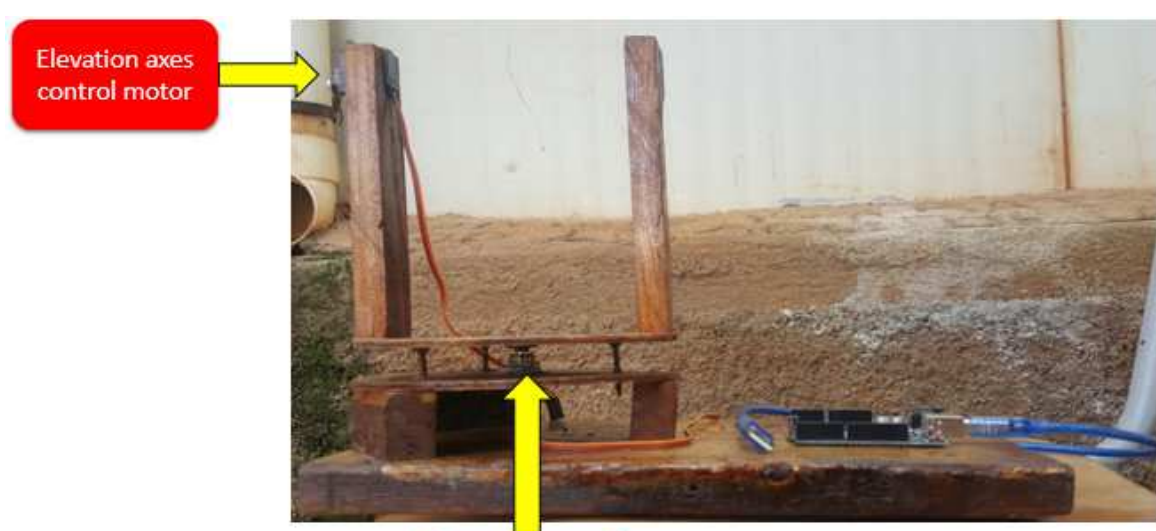

Azimuth axes

control motor

Figure 14. Arrangement of the two servo motors. 


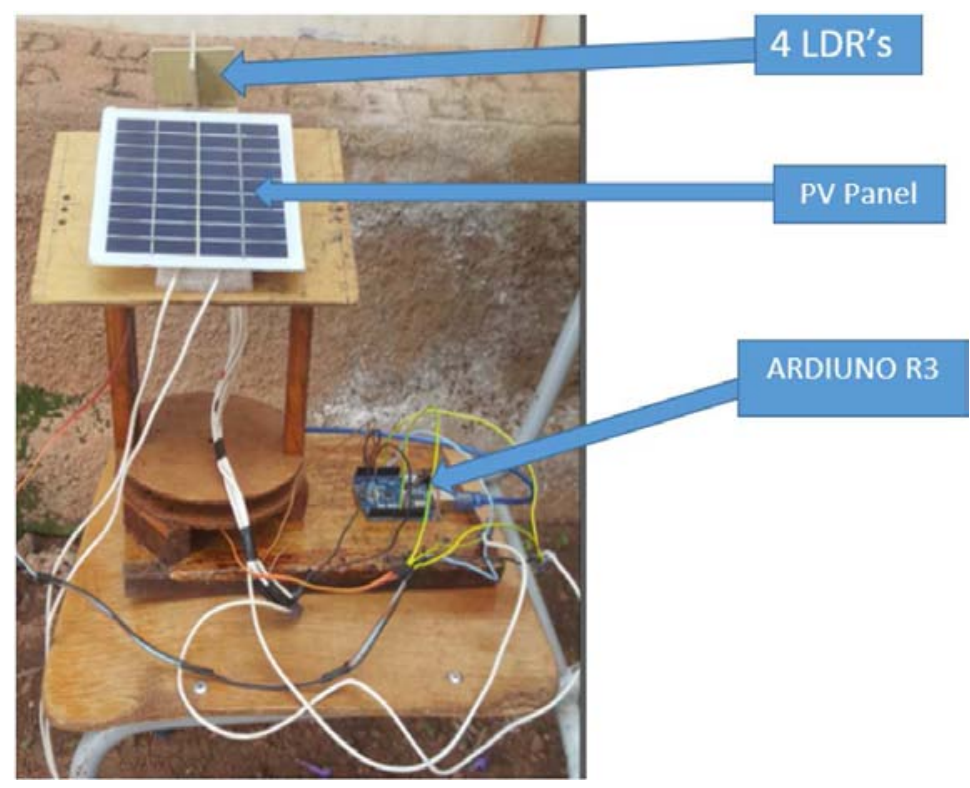

Figure 15. Arrangement of the Prototype.

\section{Conclusion}

The paper has presented a novel and an easy way of implementation of a Sun tracker that employed dual-axis with the LDR and servo motor. A laboratory prototype has been successfully built and it is tested. The performance of the developed system was experimented and compared with the static panel. Our work demonstrates that dual-axis solar tracking system can assure higher power generation compared to the static panel. The result shows that the dualaxis tracking system has $42.75 \%$ or more (if the weather condition is pleasant or sunny condition) the average power gain over the static system. A laboratory prototype has been successfully built and tested to verify the effectiveness of the control implementation. Experiment results indicated that the developed system increased the energy gain by up to $28.31 \%$ for a partly cloudy day. The prototype is achieved with low power consumption, high accuracy, and low cost. Dual-axis trackers are more efficient in tracking the sun, the additional circuitry and complexity were not required in this case.

\section{References}

[1] Williams, D. R. (1 July 2013). "Sun Fact Sheet". NASA Goddard Space Flight Center. Retrieved 12 August 2013.

[2] Bonanno, A.; Schlattl, H.; Paternò, L. (2008)."The age of the Sun and the relativistic corrections in the EOS".

[3] Woolfson, M. (2000)."The origin and evolution of the solar system". Astronomy \& Geophysics.

[4] Solar tracker http://http://en.wikipedia.org/wiki/Solar tracker.

definition:

[5] Mousazadeh, H., Keyhani, A., Javadi, A., Mobli, H., Abrinia, K., Sharifi, A. "A review of principle and sun-tracking methods for maximizing solar systems output". Renewable and Sustainable Energy Reviews. January 2009.
[6] Aashir Waleed, Dr. K M Hassan, Umar Siddique Virk, "Designing a Dual Axis Solar Tracker For Optimum Power", Journal of Electrical Engineering.

[7] Pearce, Joshua (2002)."Photovoltaics - A Path to Sustainable Futures".

[8] W. Bolton Mechatronics: Electronic Control System in Mechanical and Electrical Engineering, Addison Wesley, New York, NY, 1999.

[9] R. C. Dorf and R. H. Bishop Modern Control System, Addison Wesley, Menlo Park, CA, 1998.

[10] "Measure Light Intensity using Light Dependent Resistor (LDR)," http://www.emant.com/316002.

[11] INTRODUCTION TO THE ARDUINO MICROCONTROLLER

(https://microcontrollerslab.com/introduction-arduino-uno/).

[12] Robert Babuska, Stefano Stramigioli, Matlab and Simulink for modeling and control'.

[13] Dual-axis solar tracker: Functional model and full-scale simulations, 'French development enterprise energy solutions'. March 2013.

[14] Evaluation of the Main MPPT Techniques for Photovoltaic Applications. By MoacyrAureliano Gomes de Brito, Luigi Galotto, Jr., IEEE. IEEE TRANSACTIONS ON INDUSTRIAL ELECTRONICS, VOL. 60, NO. 3, MARCH 2013.

[15] SameerMeshram, Sharad Valvi, and NileshRaykar. 2016,"A Cost-effective Microcontroller based Sensor for Dual Axis Solar Tracking”, ISSN: 2172-038 X, No. 14 May 2016.

[16] Saeed Mansour, Dr. Wagdy R. Anis, Dr. Ismail M. Hafez. 2015, ISSN 2277-8616, VOLUME 4, ISSUE 05, MAY 2015.

[17] CeydaAksoyTirmikci and Cenk Yavuz. 2015, "Comparison of Solar Trackers and Application of a Sensor Less Dual Axis Solar Tracker", (2015) 556-561doi 10.17265/19348975/2015.06.006. 
[18] Deepthi. S, Ponni. A, Ranjitha. R and R Dhanabal. 2013, "Comparison of Efficiencies of Single-Axis Tracking System and Dual-Axis Tracking System with Fixed Mount", ISSN: 2319-5967, Volume 2, Issue 2, March 2013.

[19] Agarwal, S., and Pal, S. 2011."Design, Development, and Testing of a PC based One Axis Suntracking System for Maximum Efficiency”. Sensors \& Transducers Journal 131 (8): 75-82.

[20] Al-Haddad, M. K., and Hassan, S. S. 2011. - Low-Cost Automatic Sun Path Tracking System. \| Journal of Engineering 17 (1): 116-30.

[21] Abdallah, S., and Badran, O. 2008. "Sun Tracking System for Productivity Enhancement of Solar Stil". Desalination 220 (13): 669-76.

[22] Roth, P., Georgiev, A., and Boudinov, H. 2005. "Cheap TwoAxis Sun Following Device". Energy Conversion and Management 46 (7-8): 1179-92.

[23] Duarte, F., Gaspar, P. D., and Gonçalves, L. C. 2011. "Two Axes Solar Tracker based on Solar Maps Controlled by a Low-Power Microcontroller". Journal of Energy and Power Engineering 5 (7): 671-6.

[24] SimonEzzat, Dr. Wagdy R. Anis, and. Ismail M. Hafez. 2017," Design of photovoltaic Grid-connected using solar tracking systems", Vol. 7-No. 3, pp. 88-100, ISSN 2250-1797, MayJune 2017.

\section{Biblography}

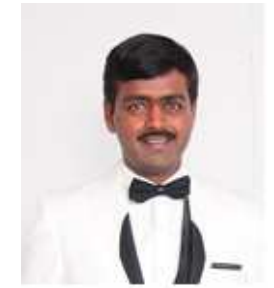

Sunil kumarJilledi was born in Tirupathi, India. Currently working as a Senior Lecturer in Mai Nefhi College of Engineering and Technology, Asmara, Eritrea. Previously he worked for the Adama Science and Technology University, Adama, Ethiopia. He is a Research Scholar at OPJS University, India. His research interests include Power Systems, Renewable Energy, Fuzzy Logic, Neural Networks, Flexible AC Transmission System (FACTS). He is working as a reviewer for many journals like International Journal of Electrical Power \& Energy Systems (Elsevier), International Journal of Scientific and Engineering Research, (IJ-ETA-ETS), Global Journal of Researches in Engineering, United States.

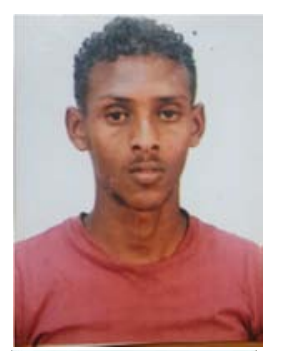

Daniel Tesfazgi was born in Asmara, Eritrea. He completed his B. S. C (Honors) in Electrical and Electronics Engineering (EEEN) in Mai-Nefhi College of Engineering and Technology. His research interest is in power system.

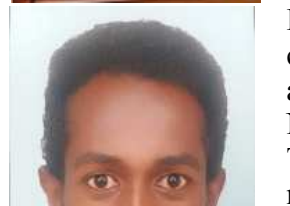

Filmon Foto was born in Asmara, Eritrea. He completed his B. S. C (Honors) in Electrical and Electronics Engineering (EEEN) in MaiNefhi College of Engineering and Technology. His research interest is in mechatronics.
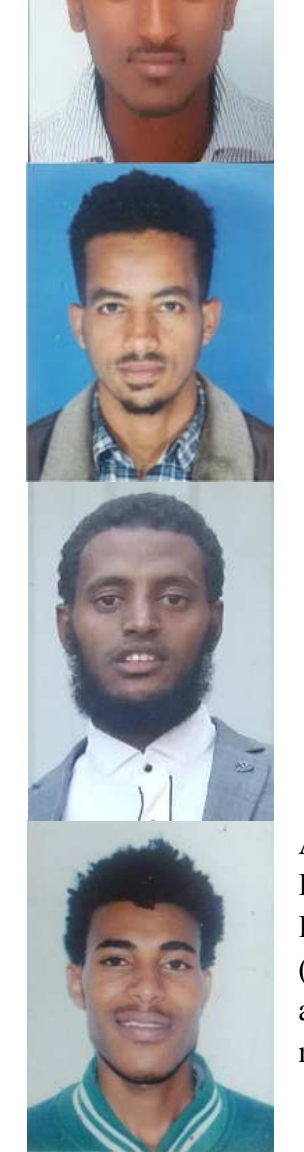

Mahmud Ali was born in Asmara, Eritrea. He completed his B. S. C (Honors) in Electrical and Electronics Engineering (EEEN) in MaiNefhi College of Engineering and Technology. His research interest is in power system.

Abduselam Atta was born in Asmara, Eritrea. He completed his B. S. C (Honors) in Electrical and Electronics Engineering (EEEN) in Mai-Nefhi College of Engineering and Technology. His research interest power system.

Alexander Yemane was born in Mendefera, Eritrea. He completed his B. S. C (Honors) in Electrical and Electronics Engineering (EEEN) in Mai-Nefhi College of Engineering and Technology. His research interest is in mechatronics. 